\title{
Poesia concreta: a crítica como problema, a poesia como desafio
}

Rogério Barbosa da Silva Centro Federal de Educação Tecnológica de Minas Gerais

\begin{abstract}
Resumo: Propóe-se refletir sobre o impacto da poesia concreta no cenário da critica e da literatura brasileira na segunda metade do século XX, com a duradoura permanência de uma polêmica acerca de sua constituiçâo e dos resgates de tradiçôes literárias. Busca-se, ainda, analisá-la sob o viés da constituição de uma linha de força de tradição inventiva no cenário da poesia, mas com imbricaçóes com outras artes, outras linguagens. A poesia concreta é, neste sentido, uma linguagem capaz de discutir a realidade brasileira, sem abrir mão da invenção.

Palavras-chave: Poesia concreta, Crítica literária, Tradiçôes criativas.
\end{abstract}

\begin{abstract}
A poesia concreta nasceu sob o signo da ruptura e da negação vanguardista, o que a predispôs, como é comum nessas formas artísticas, a um violento embate com alguns setores da sociedade, da crítica literária e artística e da própria criação poética então dominante. Assim, depois de uma série de artigos publicados nos primeiros anos da década de 1950, em suplementos culturais de jornais de São Paulo e Rio de Janeiro, ou na revista Noigandres, veículo oficial do grupo, o trio paulista - formado pelos irmãos Haroldo e Augusto de Campos, e por Décio Pignatari, que se tornariam os principais representantes da poesia concreta - publicou, em 1956, artigos-manifestos que lhe dariam forma
\end{abstract}


e conceito. Trata-se de "poesia concreta (manifesto)", de Augusto de Campos, "nova poesia: concreta (manifesto)", de Décio Pignatari, "olho por olho a olho nu (manifesto)", de Haroldo de Campos. Esses três textos, ou manifestos, não só veiculam os principais argumentos da poesia concreta, como os principais elementos que desafiavam a crítica e a poesia daquele tempo, e em certa medida ainda o fazem hoje. Não seria equivocado afirmar que, juntos, esses textos constituem o primeiro rascunho do conhecidíssimo "plano-piloto para poesia concreta", publicado em 1958 no no 4 de Noigandres, escrito num estilo irreverente, como é o comum nos manifestos.

Um ano antes, em outubro de 1955, Augusto publicara outro artigo com o mesmo título, isto é, "Poesia concreta", onde a expressão apareceu pela primeira vez:

Em sincronização com a terminologia adotada pelas artes visuais e, até certo ponto, pela música de vanguarda (concretismo, música concreta), diria eu que há uma poesia concreta. Concreta no sentido em que, postas de lado as pretensões figurativas da expressão (o que não quer dizer: posto à margem o significado), as palavras nessa poesia atuam como objetos autônomos.

Neste artigo, Augusto traça, num texto didático, a genealogia e as imbricações dessa poesia considerada "concreta", explicitando não só sua relação com as artes visuais e a música de vanguarda, como também os seus pilares linguísticos, introduzindo a noção de signo, a partir de Sartre, e a estruturação óptico-sonora funcional - perspectiva organizacional do poema, que incidirá na verbivocovisualidade ou na técnica de narração simultânea através de associações sonoras, advindas de Joyce, na espacialização visual do verso via Mallarmé, na montagem ideogrâmica, proposta por Ezra Pound, ou na atomização do verso, à maneira de e. e. cummings. No Brasil, Augusto reivindica a arquitetura cabralina, feita a "lances de vidro e cimento", já presente em Psicologia da composição e em $O$ engenheiro, além dos versos pré-concretos de Décio Pignatari e Haroldo de Campos, respectivamente, em poemas como "O jogral e a prostituta negra", de 1949, e "Ciropédia ou a Educação do Príncipe", de 1952.

1. CAMPOS, A. de. Poesia concreta, p. 55. (Grifo do autor.) 
Já no segundo texto, publicado no ํㅡㄹ 20 (novembro/dezembro) da revista ad - arquitetura e decoração, de São Paulo, em 1956, assim como nos textos de seus companheiros publicados neste mesmo número, observa-se que já se encontra fundada uma poética, cujos contornos tratam agora de definir, o que fazem Augusto de Campos, Haroldo de Campos e Décio Pignatari. Augusto começa, em "poesia concreta (manifesto)", reivindicando o compromisso da poesia concreta para com a linguagem, não mais apenas a língua. Isto é, um compromisso para além do pressuposto histórico do idioma, em que as palavras, ora transformadas em objetos dinâmicos, deixam-se contaminar por suas propriedades "psico-físico-químicas" e se dotam de antenas com as quais captam muito mais que o velho alicerce formal e silogístico-discursivo - apreendem os amplos sinais das linguagens que vibram nos meios de comunicação e que, portanto, obrigam a palavra a ser vista e vivida em sua própria facticidade (não mais apenas em sua esfera linguística) e no campo relacional de funções que ela assume no corpo visual da página. Daí a célebre síntese que encerra o texto-manifesto: "POESIA CONCRETA: TENSÃO DE PALAVRAS-COISAS NO ESPAÇO-TEMPO".

De maneira coerente e na mesma direção, o texto "nova poesia: concreta (manifesto)", de Décio Pignatari, inicia-se assinalando a crise do verso:

o verso: crise. obriga o leitor de manchetes (simultaneidade) a uma atitude postiça. não consegue libertar-se dos liames lógicos da linguagem: ao tentar fazê-lo, discursa adjetivos. não dá mais conta do espaço como condição de nova realidade rítmica, utilizando-o apenas como veículo passivo, lombar, e não como elemento relacional de estrutura. antieconômico, não se concentra, não se comunica rapidamente. destruiu-se na dialética da necessidade e uso históricos. este é apenas o golpe de misericórdia da consciência crítica: o primeiro já fora dado, de fato, por mallarmé, há sessenta anos atrás - §un coup de désø. ${ }^{4}$

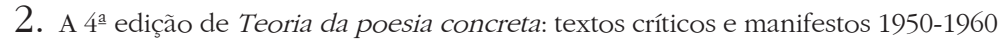
trouxe para o título dos artigos a palavra "manifesto", o que antes só constava no sumário das edições anteriores. Esta reedição, embora não se indique ser uma versão atualizada, como foi o caso da segunda, traz modificações editoriais, como, por exemplo, um índice onomástico - o que indica alguma revisão, ainda que restrita à organização textual.

3. CAMPOS, A. de. poesia concreta (manifesto), p. 72.

4. PIGNATARI. nova poesia: concreta (manifesto), p. 67. 
Nesses textos-manifestos, podemos observar um processo criativo e teórico que passa a orientar a poesia e a crítica dos irmãos Campos e de Décio Pignatari. No entanto, com objetivos nem sempre claros, a crítica, especialmente aquela que vive nos domínios da mídia impressa - mas igualmente a de poetas adversários, como têm sido Ferreira Gullar, Affonso Romano de Sant'Anna e Mário Chamie -, apressou-se a frisar de maneira condenatória a afirmação típica de manifestos sobre o fim do verso, presente no "plano-piloto para poesia concreta", ou mesmo o artigo assinado por Haroldo de Campos sobre a "matemática da composição". E denunciavam a frivolidade dessa afirmação com o fato de que todos os poetas do grupo Noigandres passariam a escrever em versos, ou, pior ainda, a se esconderem sob os versos dos poetas que traduziam. Compreender, no entanto, esse processo de formulação poética é importante para que se julgue adequadamente essa poesia, seguindo em direção contrária às polêmicas - alimentadas às vezes pelos poetas das diferentes tendências vanguardistas as quais irrompem nos jornais por ocasiões comemorativas, ou motivadas por algum artigo beligerante.

É certo que a poesia concreta, conforme aparece nesses documentos teóricos, parece-nos apresentar um escopo teórico e crítico que lhe permite não só assimilar procedimentos de diferentes linguagens (do jornal impresso, da propaganda, do rádio ou da televisão), abrindo o trabalho da poesia para um campo muito pouco explorado pelos poetas até então, como é o do designer e o das tecnologias de comunicação de massa. Assim, ao abrir o seu texto, conforme se observa no fragmento citado acima, Décio desperta o seu leitor para um comportamento já usual nos meios de comunicação, mas ainda estranho ao leitor de poesia e mesmo àqueles que vivem da criação artística. Trata-se de libertar os sentidos diante da palavra escrita, talvez no sentido que ele já nos lembrava num artigo publicado nos anos 50, intitulado "sobre poesia oral e poesia escrita":

Sinto-me aventurado a acreditar que o poeta fez do papel o seu público, moldando-o à semelhança de seu canto, e lançando mão de todos os recursos gráficos e tipográficos, desde a pontuação até o caligrama, para tentar a transposição do poema oral para o escrito, em todos os seus matizes.

5. PIGNATARI. sobre poesia oral e poesia escrita, p. 24. 
Em seu texto-manifesto, de 1956, o poeta clama por uma "arte geral da linguagem. propaganda, imprensa, rádio, televisão, cinema. uma arte popular." Essa arte não poderá ser compreendida se o gesto mallarmaico de "Un coup de dés" for esquecido, ou se esquecermos o brasileiro Oswald de Andrade, cujos versos de "epitáfio", um de seus poemas menores, de 1928, são citados por Pignatari. Essa "arte geral da linguagem" demandaria também uma poesia de criação, ao invés de uma poesia de expressão subjetiva, e condizente com as conquistas da Revolução Industrial. Por conseguinte, a palavra é vista em seu isomorfismo (captura um exemplo em Mário de Andrade), e o mistério da poesia cede espaço a uma gestalt audiovisual ("o olhoouvido ouvê"), aspecto que convoca o leitor a perceber as contribuições de Joyce, Cummings, Apollinaire, Morgenstern, Kurt Schwitters, Mallarmé, Pound e Fenollosa, Webern e Augusto de Campos. A técnica das manchetes, a montagem cinematográfica, a arquitetura implicam outras referências: Calder, Mondrian, João Cabral de Melo Neto, Cummings e Paul Klee. Décio Pignatari clama por um ideograma crítico nacional, que poderia ser, conforme se depreende a seguir no texto, algo como um catálogo de títulos publicados, isto é, os livros talvez vistos, menos em sua densidade textual, mas na sua correlação sincrônica. O texto termina, como os demais, numa declaração de princípios:

fundar uma tradição do rigor. volpi. para que o artista brasileiro não decaia depois dos quarenta.

a presente exposição: quase didática. transição do verso ao ideograma.

Assim descrita, é difícil acreditar que a poesia concreta possa ter emparedado toda uma geração a partir de $1956,{ }^{8}$, conforme chegara a declarar

6. PIGNATARI. nova poesia: concreta (manifesto), p. 67.

7. PIGNATARI. nova poesia: concreta (manifesto), p. 70.

8. Ronald Augusto resume assim a questão: "Dentre manchetes, frases de efeito francamente malcriadas e resenhas tomadas por pânico catastrófico, como o fragmento citado acima, destaco - entre tantas outras pérolas - mais uma tirada de brilho especialmente melancólico, imaginada por Affonso Romano de Sant'Anna. Ei-la: 'a poesia concretista emparedou toda uma geração a partir de 1956'. Registre-se, isso foi escrito em 1976. Logo, não me parece um absurdo interpretar este diagnóstico da seguinte maneira. O crítico parece reforçar - mirando de soslaio - a tese maledicente, sustentada por uns e outros, de que a poesia concreta colaborava indiretamente com o regime militar. Não foi por outra razão, aliás, que Autran Dourado achou por bem definir a prodigiosa militância concretista, no sentido de abrir/conquistar espaço - no âmbito de editoras, jornais e revistas -, 
Affonso Romano de Sant'Anna, e mesmo a ironizar a poesia concreta em poemas feitos à maneira concretista, como em "soneto com forma e fundo", e congêneres, ou em frases chistosas, como essa: " $\$$. Joyce certamente escreveu o Finnegans Wake, viveu em Trieste e sabia mil línguas, mas morreu, e isto é grave, sem ter lido o Plano-Piloto da Poesia Concreta." É uma posição que renega uma lúcida apreciação realizada no artigo "Concretismo: consequências e perspectivas da poesia brasileira", publicado no Suplemento Literário de Minas Gerais, em 1967:

Sob certo ponto de vista, o concretismo é uma tentativa de resposta a tese de João Cabral de Melo Neto no Congresso de Escritores de São Paulo, em 1945, quando o poeta de "Faca só lâmina" confessou seu dilema: usava ainda o verso da maneira mais honesta e limpa que podia, mas reconhecia que o mundo moderno oferecia através de todos os diversos meios de comunicação, um desafio perturbador e que o poeta não soubera até então como responder, preferindo ignorá-lo na praticância tradicional do poema puramente literário. Quando o concretismo em seu plano piloto assinala como "encerrado o ciclo histórico do verso (unidade rítmico-formal)" e advoga para o poeta todas as liberdades latentes de expressão poética, estava pondo em cheque (sic) a posição do poeta dentro da sociedade e retomando com características novas e autênticas o problema já exposto por Vigny em sua peça "Chatterton": onde o herói (na verdade o anti-herói) é o poeta expulso de seu paraíso pela sociedade burguesa industrial que já não o aceita como orientador, uma vez que ele não tem os elementos técnicos capazes de a entretener (sic) e a dirigir. Assim, o concretismo ao mesmo tempo em que denuncia o desemprego do poeta tenta otimisticamente reempregá-lo a seu modo no seu contexto social, pondo-lhe na mão os instrumentos os mais "up-to-date" que existem: o computador e todos os meios modernos da técnica de publicidade, lembrando-o das pesquisas da cibernética, da física aleatória e da "masscomunication". ${ }^{10}$

8....de modo a dar mais visibilidade às suas idéias, em termos de que esse exercício assumia a forma de um 'poder quase ditatorial'." (AUGUSTO, R. Disponível em: http://www.nao-til.com.br/nao-80/ronald.htm. Acesso em: 26 mar. 2012.)

9. SANT'ANNA. Poesia reunida, p. 158.

10. SANT'ANNA. Concretismo: consequências e perspectivas da poesia brasileira II, p. 2. 
Parece-nos correta a avaliação de Sant'Anna neste artigo de 1967, uma vez que não só corrobora um depoimento de um poeta da estatura de João Cabral, como lê de maneira isenta o plano-piloto. A declaração é contundente e consoante à postura que os novos poetas, concretos, viriam a tomar frente ao seu tempo. Não é outra a conclusão a que Haroldo de Campos chegara em seu texto-manifesto "olho por olho a olho nu (manifesto)", quando conclui que a POESIA CONCRETA seria

a linguagem adequada à mente criativa

contemporânea

permite a comunicação em seu grau + rápido

prefigura para o poema uma reintegração na vida cotidiana semelhante à $\mathrm{q}$ o BAUHAUS propiciou às artes visuais: quer como veículo de propaganda comercial (jornais, cartazes, TV, cinema etc.), quer como objeto de pura fruição (funcionando na arquitetura, p. ex.), com campo de possibilidades análogo ao do objeto plástico

substitui o mágico, o místico e o maudit pelo ÚTIL

TENSÃO para um novo mundo de formas

$$
\begin{aligned}
& \text { VETOR } \\
& \text { para }
\end{aligned}
$$

O

$$
\text { FUTURO }^{11}
$$

Tal como seus companheiros o fizeram, Haroldo de Campos relê os autores do paideuma concreto, apontando os aspectos de um programa para uma nova arte, isto é, uma poesia em que "a palavra tem uma dimensão GRÁFICOESPACIAL, uma dimensão ACÚSTICO-ORAL, uma dimensão CONTEUDÍSTICA.” Desta maneira, propõe uma poesia que "assedia o OBJETO mentado em suas plurifacetas: previstas ou imprevistas: veladas ou reveladas: num jogo de espelhos ad infinitum [...]". ${ }^{12}$ Quer dizer, a poesia concreta traria em seu próprio fazer, como proposta, a possibilidade de uma obra como work in progress, aberta e sujeita a infinitas versões. Além disso, em sua faceta de jogo, portanto, de trabalho calculado, ela permitiria também o imponderável, a capacidade de a

11. CAMPOS, H. de. olho por olho a olho nu (manifesto), p. 76.

12. CAMPOS, H. de. olho por olho a olho nu (manifesto), p. 74 . 
linguagem revelar mais do que a manipulação do código sugere, na medida em que o poema revela também a medula da linguagem, ou sua capacidade infrassignificativa, como queria Roland Barthes, em seu "rumor da língua".

Pensando ainda em seu impacto no espaço da crítica e da própria apreensão da poesia como arte da linguagem, é preciso pensar a articulação que a poesia concreta estabelece em nível internacional, ao adquirir também uma dimensão de linguagem "transnacional". Uma afirmação recorrente entre poetas e críticos ligados à poesia concreta ou a outros experimentalismos é a transnacionalidade da linguagem poética, pois muitos poemas concretos e visuais evidenciam que essa é uma forma de poesia que, em geral, não necessita ser traduzida. Evidentemente, isso se torna mais verdadeiro na medida em que a propensão visual do poema possa ser mais explorada que os recursos idiomáticos do texto. Esse fato talvez seja indicador do sucesso internacional dessa poesia, que se alastrou, rapidamente, por várias partes do mundo. No Brasil, embora os próprios poetas concretos tenham organizado, na edição de Teoria da poesia concreta, uma sinopse de sucessos internacionais do movimento, não são comuns estudos que abordem a poesia concreta por este viés. A exceção, nesse caso, é Philadelpho Menezes, cujos trabalhos teórico-criativos foram sempre um diálogo com a poesia concreta, neoconcreta, poema-processo e outras poéticas visuais - trabalhos que tiveram o mérito de perspectivar os experimentalismos poéticos nacional e internacionalmente. Isso pode ser verificado percorrendo-se as páginas de A crise do passado (2001), um estudo instigante sobre as poéticas da modernidade, da Renascença aos nossos dias, e Poética e visualidade (1991), um dos raros estudos sobre visualidade na poesia brasileira.

Excetuando-se os ensaios de Philadelpho Menezes, a fortuna crítica sobre a poesia concreta só começa a crescer em meados da década de 90, com o aumento de teses universitárias sobre o tema, algumas já transformadas em livros. Destaca-se a de Marlene Holzhausen, Poesia concreta: dois percursos, um diálogo, que fundamenta o diálogo entre os poetas de São Paulo e Eugen Gomringer, contextualizando o surgimento e a valorização da arte concreta no triângulo Suíça/Alemanha/Brasil, sua entrada, via Argentina, até o profícuo diálogo entre os paulistas e Gomringer. Importante percurso, pois, como assinala a autora:

Parte das dificuldades, das resistências e dos equívocos que, muitas vezes, bloqueiam a compreensão, dispersam ou radicalizam as inúmeras discussões sobre a Poesia Concreta, nascem da nebulosidade que envolve este período. O fio condutor deste traçado original, descrito pelo poeta 
suíço-boliviano e pelos poetas brasileiros, diretamente vinculados aos momentos iniciais da Poesia Concreta, se perdeu ao longo dos anos no emaranhado das críticas. ${ }^{13}$

São, porém, poucos os estudos que abordam o concretismo numa perspectiva geográfica mais ampla. Embora, em seus artigos e manifestos teóricos, o grupo Noigandres raramente se refira à existência de um movimento internacional da poesia concreta, verificamos seu empenho em situar sua produção poética como parte de uma grande constelação de poesia inventiva, numa dimensão trans-histórica, o mesmo acontecendo com a seleção e organização da poesia por eles traduzida.

Isso mostra que os poetas concretos estavam conscientes de que produzir poesia de vanguarda significa responder criticamente às questões postas presentemente num plano nacional e internacional. Esse é o teor de um dos artigos publicados em Teoria da poesia concreta, escrito originalmente como introdução a uma antologia organizada pelo grupo concretista do Ceará, em julho de 1960, intitulado "contexto de uma vanguarda". Nesse artigo, Haroldo de Campos justifica o projeto da poesia concreta brasileira como sendo afinado com o momento político de modernização do país. Por analogia, o poeta relaciona a criação de Brasília em pleno centro-oeste à organização de um movimento de poesia concreta no Ceará. Análogo a isso é o fato de que, nessa comparação, figurasse a vanguarda como elemento gerador de desenvolvimento da arte e das condições socioculturais na periferia do país. Haroldo de Campos associa, desse modo, fatores políticos e estéticos, para evidenciar o anacronismo de um regionalismo à moda romântica, ainda corrente na cultura brasileira. Esse ponto de vista resultava, segundo Campos, na integração dessas regiões periféricas a partir de uma conotação exótica. Assim, Haroldo de Campos vê a organização de um movimento de poesia concreta no Ceará como força positiva na formação de uma consciência crítica em consonância com as grandes transformações sociais que se operavam na consolidação de um projeto moderno para o Brasil.

A partir de seu texto, podemos verificar que Haroldo de Campos expressa a utopia que envolvia o movimento concretista e que ele sente a

13. HOlZHAUSEN. Poesia concreta: dois percursos, um diálogo, p. 239. 
afinidade do grupo cearense com a poesia concreta paulista como um indício da força desta última, o que se verifica no seguinte trecho:

Pela primeira vez - e diz-se isto como verificação objetiva, sem implicação de qualquer juízo de valor - a poesia brasileira é totalmente contemporânea, ao participar na própria formulação de um movimento poético de vanguarda em termos nacionais e internacionais, e não simplesmente em sentir-lhe as conseqüências com uma ou muitas décadas de atraso, como é o caso até mesmo do movimento de 22 . $^{14}$

Nesse momento, Haroldo identifica a "poesia brasileira contemporânea" como sinônimo de poesia concreta, ou no mínimo, de poesia de vanguarda. Evidentemente, esse sentido ampliado, por ele proposto, incomoda e incomodou muitos poetas, mas, ao proceder dessa maneira, o autor desejava explicitar que a garantia de ser esta uma poesia contemporânea resulta de sua capacidade e claro desejo de formular questões supranacionais. Se, num primeiro instante, sentimos um tom exagerado em sua formulação, um olhar mais atento nos revela a sintonia de sua teoria como ponto de vista de seus pares internacionais. Nesse texto, o poeta reafirma ser um valor para a poesia concreta o seu nascimento concomitante no Brasil e na Suíça, ressaltando que a brasileira nasceu da "meditação de conquistas formais perfeitamente caracterizadas no âmbito de nossa história poética, como sejam os poemas-minuto de Oswald de Andrade e o construtivismo poemático de um João Cabral de Melo Neto [...]." ${ }^{15}$

Eis aqui um território também espinhoso para a crítica da poesia concreta, uma vez que, como diz Marcos Siscar, no Brasil há um peso da ideologia romântica, vitoriosa, por exemplo, na Formação da literatura brasileira, de Antonio Candido, que orienta um discurso da nacionalidade como ponto de vista sobre o Brasil. ${ }^{16}$ A partir de um comentário de Roberto Schwarz, o autor afirma que,

Aqui [no Brasil] as coisas se apresentam funcionalmente como postiças ou inautênticas. Ou seja, a descrição (da leitura comum de um estado de coisas) transforma-se rapidamente, talvez muito rapidamente, em uma prescrição (de qual deve ser a leitura desse estado de coisas). O regime discursivo

14. CAMPOS, H. de. contexto de uma vanguarda, p. 211.

15. CAMPOS, H. de. contexto de uma vanguarda, p. 211-212.

16. Cf. SISCAR. O discurso da história na teoria literária brasileira, p. 106. 
da interpretação é aqui substituído por aquilo que estou chamando de um regime discursivo do fato, fato este que não voltará a ser questionado. ${ }^{17}$

Deriva daí, ainda segundo o autor, um argumento de ruptura do diálogo, de assentimento anti-intelectual, ou até, uma forma de censura. ${ }^{18}$ É nesse sentido, talvez, que se pode apreender uma considerável parcela de crítica à poesia concreta, quando se remonta aos embates, seja entre Augusto de Campos e Roberto Schwarz, a propósito do poema "pós-tudo", ou ainda entre Haroldo de Campos e Antonio Candido, em relação à pertença de Gregório de Matos à literatura brasileira.

Leda Tenório da Motta estuda essa tensão, contrapondo a trajetória intelectual de Antonio Candido, no contexto da revista Clima e da redação, em meados dos anos 40, de Formação da literatura brasileira, publicada em 1959, à gênese dos textos do grupo Noigandres, entre 1952 e 59. Ela demonstra que, mais do que uma coincidência, essas produções dão a ver as linhas de força explicativas do Brasil, as quais aquecem essa guerrilha em torno da literatura brasileira e da periferia cultural. A partir de uma pesquisa etimológica da palavra, questiona se "clima" não dirá respeito metaforicamente à nossa "inclinação ou latitude de país periférico em relação à linha equatorial de referência dos centros metropolitanos em torno dos quais gravitamos, segundo a idéia tão recorrente da plataforma do mesmo nome?" ${ }^{19}$ Ao se deter sobre a Formação, retoma a metáfora de Candido sobre a literatura brasileira como um "galho secundário" do "arbusto de segunda ordem no jardim das musas", e deduz que o texto magno da historiografia brasileira nos levaria a associar a literatura brasileira à ideia de "aclimatação", ou de uma floração da semente que vingou em outras paragens. ${ }^{20}$ Por seu turno, Noigandres se orienta por apropriação, via Pound, de uma "bandeira onomástica" que ligaria nossa literatura ao trovadorismo, pois a palavra saltaria "das fontes mais remotas da lírica européia para o presente brasileiro".

17. SISCAR. O discurso da história na teoria literária brasileira, p. 107. (Grifo do autor.)

18. SISCAR. O discurso da história na teoria literária brasileira, p. 113.

19. мОтTA. Quando é "pós-tudo"? Sobre Clima e Noigandres, as revistas, os grupos, os parti pris, p. 51. (Grifo da autora.)

20. MOTTA. Quando é "pós-tudo"? Sobre Clima e Noigandres, as revistas, os grupos, os parti pris, p. 52.

21. мотTA. Quando é "pós-tudo"? Sobre Clima e Noigandres, as revistas, os grupos, os parti pris, p. 53. 
O resultado óbvio dessas trajetórias é o confronto da tese do desenraizamento com a ideologia romântica de Formação da literatura brasileira.

No caso da polêmica envolvendo Augusto de Campos e Roberto Schwarz, depois de analisar aspectos da leitura que o sociólogo fez do poema de Augusto, a autora ressalva a importância de se ater ao debate, já longe da guerra de posições na mídia, para entender a exponenciação das diferenças. Para ela, trata-se mesmo de dois modos de ver a tradição, um tema que "mobilizou a geração de1922, com as conseqüências bifurcantes (Mário/Oswald) que conhecemos". ${ }^{22}$ Ou seja, a polêmica está condicionada à visão do Brasil como país periférico e, portanto, subdesenvolvido, contra a perspectiva antropofágica e desenraizada. Por conseguinte, questiona Schwarz:

Trabalhando na hipótese do atraso e da mimetização próprios de nossa incivilidade, há um relógio, ou muitos relógios, marcando nosso atraso, na obra do autor de Que horas são? O mesmo relógio que lá está, aliás, cumprindo pontualmente seu papel, nas tentativas de enquadramento temporal - onde e quando é tudo isso? - do poema de Augusto, como vimos. $^{23}$

De fato, o que se observa é que a recepção crítica da poesia concreta ainda é vista pelos valores que orientam o posicionamento ideológico e que, por vezes, terminam camuflados pelas certezas em torno deles, como já apontamos. Em se tratando das contaminações da poesia concreta pelas transformações da indústria cultural, Leda Tenório aproveita para delimitar outra diferença substancial entre as duas correntes de pensamento. Ressalta que o grupo de Clima, ainda que busque caracterizá-la como uma publicação eclética e multidisciplinar, pelas diferentes formações do próprio grupo, não chega a explorar o texto literário nas relações internas entre as linguagens, ainda que abordem o cinema, o teatro e a música na revista, e, ainda que publiquem propagandas diversas, não chegam a estabelecer relações entre o texto e a linguagem publicitária. Ou seja, os objetos abordados constituem entidades estanques, o texto literário não é pensado enquanto montagem e nem se observam as contaminações de

22. мОTTA. Quando é "pós-tudo"? Sobre Clima e Noigandres, as revistas, os grupos, os parti pris, p. 73.

23. мотTA. Quando é "pós-tudo"? Sobre Clima e Noigandres, as revistas, os grupos, os parti pris, p. 72-73. 
linguagens na abordagem dos temas discutidos em seus números. Por outro lado, o grupo de poetas em torno de Noigandres estende a prática poética para além da linguagem verbal, a começar pelo próprio design da revista.

Isso faz sentido se realizamos uma leitura atenta dos próprios manifestos e textos críticos da poesia concreta. Em síntese, o fato de se haverem lançado nessa aventura planificada de uma poesia não enclausurou nenhum dos poetas que articularam o movimento no Brasil. Pelo contrário, após meio século, é possível ver a coerência e a singularidade da poesia de cada um dos membros do grupo de Noigandres. O interesse pela música, no caso de Augusto, a motivação pela teoria e pela crítica, no caso de Haroldo e Décio, e a atração pela tradução, no caso dos três, somente arejou e revelou a importância, em nosso meio, da consciência crítica e do próprio exercício da crítica por poetas - algo por que clamava Mário Faustino nos idos de 1950.

Concrete Poetry: criticism as problem, poetry as challenge

Abstract: This work intends to reflect about the impact of Concrete Poetry in the context of criticism and Brazilian literature in the second half of the twentieth century, with the lasting permanence of a controversy about its creation and redemptions of literary traditions. The aim is also to analyze it under the bias of the establishment of a power line in the scenario of inventive tradition of poetry, but with overlaps with other arts, and other languages. Concrete poetry is, in this sense, a language capable of discussing the Brazilian reality, without compromising the artistic invention.

Keywords: Concrete poetry, Literary criticism, Creative traditions. 


$$
\text { Referências }
$$

AUGUSTO, Ronald. A santificação transformada. In: [Não 80]. Disponível em: <http:// www.nao-til.com.br/nao-80/ronald.htm>. Outubro 2004. Acesso em: 26 mar. 2012.

CAMPOS, Augusto de. poesia concreta; poesia concreta (manifesto). In: CAMPOS, A. de; PIGNATARI, D.; CAMPOS, H. de. Teoria da poesia concreta: textos críticos e manifestos. Cotia: Ateliê, 2006. p. 55-57, 71-72.

CAMPOS, Haroldo de. olho por olho a olho nu (manifesto); contexto de uma vanguarda. In: CAMPOS, A. de; PIGNATARI, D.; CAMPOS, H. de. Teoria da poesia concreta: textos críticos e manifestos. Cotia: Ateliê, 2006. p. 73-76, 209-214.

Holzhausen, Marlene. Poesia concreta: dois percursos, um diálogo - Tese de doutoramento em literatura alemã. São Paulo: USP, 1996. (mimeo)

MOTTA, Leda Tenório da. Quando é "pós-tudo"? Sobre Clima e Noigandres, as revistas, os grupos, os parti pris. In: MOTTA Leda T. Sobre a crítica literária brasileira no último meio século. Rio de Janeiro: Imago, 2002. p. 43-87.

PIGNATARI, Décio. sobre poesia oral e poesia escrita; nova poesia: concreta (manifesto). In: CAMPOS, A. de; PIGNATARI, D.; CAMPOS, H. de. Teoria da poesia concreta: textos críticos e manifestos. Cotia: Ateliê, 2006. p. 23-28, 67-70.

SANT'ANNA, Affonso R. de. Concretismo: conseqüências e perspectivas da poesia brasileira II. In: Suplemento Literário de Minas Gerais. Belo Horizonte: Imprensa Oficial, v. 2, n. 42, p. 2, jun. 1967.

SANT'ANNA, Affonso R. de. Poesia reunida - 1965-1959. Porto Alegre: L\&PM, 2004, v. 1.

SISCAR, Marcos. O discurso da história na teoria literária brasileira. In: SANTOS, Alcides C. dos; DURÃO, Fábio A.; SILVA, Maria das Graças G. Villa da. (Orgs.) Desconstruções e contextos nacionais. Rio de Janeiro: 7Letras, 2006. p. 102-114. 